\title{
Medication Overuse and Headache Burden
}

\section{Results From the CaMEO Study}

Todd J. Schwedt, MD, Dawn C. Buse, PhD, Charles E. Argoff, MD, Michael L. Reed, PhD, Kristina M. Fanning, PhD, Cory R. Hussar, PhD, Aubrey Manack Adams, PhD, and Richard B. Lipton, MD

Neurology: Clinical Practice June 2021 vol. 11 no. 3 216-226 doi:10.1212/CPJ.0000000000001037

\author{
Correspondence \\ Dr. Lipton \\ Richard.Lipton@einstein.yu.edu
}

\section{Abstract \\ Objective}

To estimate the relative frequency of acute medication overuse (AMO) among people with episodic migraine and chronic migraine, to characterize the types of acute medications overused for migraine, and to identify factors associated with AMO.

\section{Methods}

We analyzed data from the Chronic Migraine Epidemiology and Outcomes (CaMEO) Study (ClinicalTrials.gov, NCT01648530), a crosssectional and longitudinal internet study that included a systematic sampling of the US population. From September 2012 to November

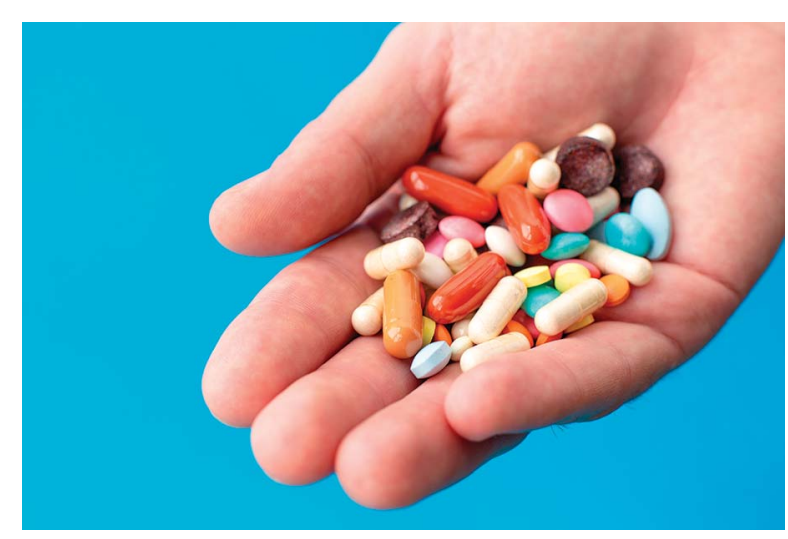
2013, the CaMEO Study respondents participated in different modules to collect data on the clinical course of migraine, family burden, barriers to care, endophenotypes, and comorbidities. Among people who met the criteria for migraine consistent with the International Classification of Headache Disorders, third edition (ICHD-3), we evaluated types and frequency of medications used for headache/migraine, selected comorbidities, and emergency department (ED) and urgent care (UC) use. AMO was defined by days per month of medication use as specified by ICHD-3 criteria for medication overuse headache $(\mathrm{MOH})$ without the requirement for $\geq 15$ monthly headache days (MHDs). Nested, multivariable binary logistic regression modeling was used to identify factors associated with an increased risk of AMO.

\section{Results}

Of 16,789 CaMEO respondents with migraine, 2,975 (17.7\%) met the AMO criteria. Approximately $67.9 \%(2,021 / 2,975)$ of AMO respondents reported $<15$ MHDs. Simple analgesics, combination analgesics, and opioids were the medication classes most commonly overused. Factors associated with AMO in the final multivariable logistic regression model included $\geq 15$ MHDs, moderate to severe disability, severe migraine interictal burden, use of preventive medication, and an ED/UC visit for headache within 6 months.

\section{Conclusions}

Approximately two-thirds of respondents with AMO reported $<15$ MHDs and therefore did not meet the criteria for $\mathrm{MOH}$. Those with $\mathrm{AMO}$ had greater disease burden and increased $\mathrm{ED} / \mathrm{UC}$ utilization relative to people with migraine but not AMO. 
Migraine is a prevalent chronic neurologic disease characterized by painful, debilitating attacks. ${ }^{1-3}$ The goal of acute treatment is to relieve symptoms and restore function. ${ }^{4}$ Current acute treatments are often inadequately effective, contributing to the need for more frequent dosing and overuse, thereby substantially increasing migraine burden as well as the risk of disease progression. ${ }^{5-10}$

Medication overuse headache $(\mathrm{MOH})$ is defined by the International Classification of Headache Disorders, third edition (ICHD-3) as headache occurring $\geq 15$ days per month in individuals with a preexisting headache disorder and regular overuse of acute medications for more than 3 months. ${ }^{11} \mathrm{MOH}$ implies that overuse of medication is causally related to headaches, representing a secondary headache disorder. By contrast, acute medication overuse (AMO) refers to taking specific medications $\geq 10$ days per month for most medications or $\geq 15$ days per month for simple analgesics. Consequently, some people with AMO may not meet the headache-day criteria for $\mathrm{MOH}$. In addition, some people may use medications on headache-free days in anticipation of migraine or for other pain disorders. ${ }^{12}$ Thus, the number of days taking migraine acute medications can exceed the number of migraine or headache days. ${ }^{13}$

The goal of this analysis of the Chronic Migraine Epidemiology and Outcomes (CaMEO) Study data was to estimate the relative frequency of AMO and to characterize the types of acute medications overused. We also sought to identify sociodemographic features, headache characteristics, emergency health care resource utilization, and migraine-related burden in people with and without AMO.

\section{Methods}

\section{Study Design}

CaMEO was a cross-sectional and longitudinal web-based survey that included a systematic sampling of the US population as previously described. ${ }^{14}$ From September 2012 to November 2013, the CaMEO Study respondents participated in different modules to collect data on the clinical course of migraine, family burden, barriers to care, endophenotypes, and comorbidities.

The present cross-sectional analysis used data from the baseline screening module, core module, and endophenotype module. The baseline screening module covered sociodemographic information (age, body mass index [BMI], sex, employment, income, race/ethnicity, education, and marital status) and health information related to medical conditions, including headaches, pain disorders, and other conditions. The core module addressed headache frequency over the last 3 months (number of days). The frequency of medication use over the last 30 days (number of days and how many times per day the medication was used) was addressed by the question "Which of these medications (if any) are you currently using (or typically keep on hand) to treat your headaches?". The core module also addressed the type of medication used to treat headache, emergency health care resource use in the past 6 months (number of times each resource was used), number of nights spent in the hospital in the past 6 months related to headaches, and Generalized Anxiety Disorder 7-Item Scale (GAD-7), 9Item Patient Health Questionnaire (PHQ-9), Migraine Interictal Burden Scale (MIBS-4), and Migraine Disability Assessment (MIDAS) questionnaire results. The endophenotype module assessed migraine features, including the presence of allodynia (using the 12-Item Allodynia Symptom Checklist [ASC-12] and 5-point frequency allodynia screener) and other comorbidities (appendix e-1, links.lww.com/CPJ/A259).

\section{Study Respondents and Outcomes}

Study respondents who met the modified ICHD-3 migraine criteria, assessed using the validated American Migraine Study (AMS)/American Prevalence and Prevention (AMPP) migraine diagnostic module, were entered into the study (note: the AMS/ AMPP diagnostic module was based on ICHD-2 migraine criteria, ${ }^{14,15}$ but no significant changes occurred among the ICHD- $2,{ }^{15}$ ICHD-3-beta, ${ }^{16}$ and the final ICHD- ${ }^{11}$ criteria related to classification of migraine). Responses to the core module were used to categorize respondents who met the AMO criteria for any single class of medications or for multiple classes. Respondents were categorized according to monthly headache frequency (calculated from a 3-month report period) of 0-4 days, 5-9 days, 10-14 days, or $\geq 15$ MHDs. Headache characteristics were assessed in the AMO and non-AMO groups.

Patient-reported outcomes for both groups included PHQ-9, GAD-7, MIDAS, MIBS-4, ASC-12, and Migraine Severity Symptom Score (MSSS). Additional information for all assessments can be found in appendix e-1 (links.lww.com/CPJ/A259).

Emergency health care resource utilization as determined by frequency of emergency department (ED) and urgent care (UC) facility use for headache in the past 6 months was assessed in the AMO and non-AMO groups. The self-reported medical diagnosis of comorbidities reported in the endophenotype module was organized by system organ classes of the Medical Dictionary for Regulatory Activities, and comorbidities that occurred in more than 5\% of the CaMEO respondents were reported by AMO status within MHD groups.

\section{Defining AMO}

To establish an operational definition for overuse by acute medication class, we chose medication use days per month criteria consistent with medication use rates in ICHD-3 criteria for $\mathrm{MOH}$; AMO was identified from ICHD-3 criteria for single medication class and multiple medication class overuse. The single-class AMO group included respondents who met the AMO criteria for at least 1 class of medication: (1) use of naproxen sodium, aspirin, ibuprofen, acetaminophen, or prescription nonsteroidal anti-inflammatory drugs (NSAIDs) for $\geq 15$ days per month or (2) use of any ergotamine, triptan, opioid, or combination analgesics (including Excedrin, barbiturates, and Midrin) for 10 or more days per 
Table 1 Baseline Characteristics and Sociodemographics by AMO Status

\begin{tabular}{|c|c|c|c|}
\hline & AMO $(n=2,975)$ & Non-AMO $(n=13,814)$ & $p$ Value $^{a}$ \\
\hline Age, y, mean (SD) & $43.2(13.8)$ & $40.7(14.5)$ & $<0.001^{b}$ \\
\hline Female & $2,297(77.2)$ & $10,198(73.8)$ & $<0.001$ \\
\hline White race & $2,547(85.9)$ & $11,497(83.5)$ & $<0.01$ \\
\hline Obese $\left(\mathrm{BMI} \geq 30 \mathrm{~kg} / \mathrm{m}^{2}\right.$ ) & $1,255(42.2)$ & $4,664(33.8)$ & $<0.001$ \\
\hline Income $\geq \$ 50,000$ & $1,621(54.8)$ & $8,311(60.6)$ & $<0.001$ \\
\hline Employed & $1,945(65.4)$ & $9,826(71.1)$ & $<0.001$ \\
\hline College degree (4-y) & $1,183(39.8)$ & $6,364(46.1)$ & $<0.001$ \\
\hline \multicolumn{4}{|l|}{ Monthly headache days } \\
\hline Median (IQR) & $10.0(4.3,16.7)$ & $2.0(1.0,4.7)$ & $<0.001^{c}$ \\
\hline Mean (SD) & $11.2(8.2)$ & $3.7(4.4)$ & $<0.001^{b}$ \\
\hline Monthly headache frequency category & & & $<0.001$ \\
\hline $0-4 d$ & $783(26.3)$ & $10,376(75.1)$ & \\
\hline $5-9 d$ & $688(23.1)$ & $2,217(16.0)$ & \\
\hline $10-14 \mathrm{~d}$ & $550(18.5)$ & $699(5.1)$ & \\
\hline$\geq 15 \mathrm{~d}$ & $954(32.1)$ & $522(3.8)$ & \\
\hline Diagnosed with migraine & $1,886(63.4)$ & $5,781(41.8)$ & $<0.001$ \\
\hline Allodynia (ASC $\geq 3$ ) & $1,351(60.3)$ & $4,469(42.3)$ & $<0.001$ \\
\hline MSSS, median (IQR) & $17.0(14.0,19.0)$ & $15.0(13.0,18.0)$ & $<0.001^{\mathrm{c}}$ \\
\hline $\begin{array}{l}\text { Headache currently managed by a } \\
\text { specialist (neurologist, pain, or headache) }\end{array}$ & 355 (11.9) & $414(3.0)$ & $<0.001$ \\
\hline \multicolumn{4}{|l|}{ PHQ-9 } \\
\hline Moderate-severe depression (score $\geq 10$ ) & $1,602(53.8)$ & $3,823(27.7)$ & $<0.001$ \\
\hline Median (IQR) & $10.0(5.0,16.0)$ & $5.0(2.0,10.0)$ & $<0.001^{\mathrm{c}}$ \\
\hline \multicolumn{4}{|l|}{ GAD-7 } \\
\hline Moderate-severe anxiety (score $\geq 10$ ) & $1,447(48.6)$ & $3,575(25.9)$ & $<0.001$ \\
\hline Median (IQR) & $9.0(5.0,14.0)$ & $6.0(2.0,10.0)$ & $<0.001^{c}$ \\
\hline \multicolumn{4}{|l|}{ MIBS } \\
\hline $\begin{array}{l}\text { Moderate-severe interictal burden } \\
\text { (score } \geq 3)\end{array}$ & $1,933(65.0)$ & $4,423(32.0)$ & $<0.001$ \\
\hline Median MIBS score (IQR) & $4.0(1.0,8.0)$ & $0.0(0.0,4.0)$ & $<0.001^{\mathrm{c}}$ \\
\hline \multicolumn{4}{|l|}{ MIDAS } \\
\hline Moderate-severe disability (score $\geq 11$ ) & $2,174(73.1)$ & $4,365(31.6)$ & $<0.001$ \\
\hline Median (IQR) & $23.0(10.0,50.0)$ & $6.0(2.0,14.0)$ & $<0.001^{c}$ \\
\hline $\begin{array}{l}\text { ED/UC use for headache ( } \geq 1 \text { visit in past } \\
6 \mathrm{mo} \text { ) }\end{array}$ & $380(12.8)$ & $453(3.3)$ & \\
\hline
\end{tabular}

Abbreviations: $\mathrm{AMO}=$ acute medication overuse; $\mathrm{ASC}=$ Allodynia Symptom Checklist; $\mathrm{BMI}=$ body mass index; $\mathrm{ED}=$ emergency department; $\mathrm{GAD}-7=$ Generalized Anxiety Disorder 7-Item Scale; HCP = health care professional; IQR = interquartile range; MIBS = Migraine Interictal Burden Scale; MIDAS = Migraine Disability Assessment Scale; MSSS = Migraine Symptom Severity Score; PHQ-9 = 9-Item Patient Health Questionnaire; UC = urgent care.

Data are $\mathrm{n}(\%)$ unless otherwise indicated.

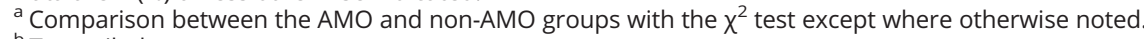

${ }^{\mathrm{b}}$ Two-tailed $t$ test.

${ }^{\mathrm{c}}$ Mood median test. 
Table 2 Single-Medication Use, Single-Class AMO, and Overall AMO Among People With Migraine in CaMEO

\begin{tabular}{|c|c|c|c|c|c|}
\hline \multirow[b]{2}{*}{ Medication } & \multicolumn{2}{|c|}{ Acute medication use } & \multicolumn{3}{|c|}{ Overusing individual medication classes } \\
\hline & $\mathrm{N}$ & $\%$ of CaMEO population ${ }^{a}$ & $\mathrm{~N}$ & $\%$ of medication class users ${ }^{b}$ & $\%$ of CaMEO population ${ }^{a}$ \\
\hline $\begin{array}{l}\text { Any single-class acute medication use for } \\
\text { headache }\end{array}$ & 14,936 & 89.0 & 2,753 & 18.4 & 16.4 \\
\hline Simple analgesic & 13,209 & 78.7 & 1,767 & 13.4 & 10.5 \\
\hline NSAID ( $\left.R_{\mathbf{x}} / O T C\right)$ & 10,215 & 60.8 & 1,218 & 11.9 & 7.3 \\
\hline Acetaminophen & 6,516 & 38.8 & 506 & 7.8 & 3.0 \\
\hline Aspirin & 3,025 & 18.0 & 310 & 10.2 & 1.8 \\
\hline Combination analgesic $^{c}$ & 5,113 & 30.5 & 938 & 18.3 & 5.6 \\
\hline Opioid & 1,947 & 11.6 & 422 & 21.7 & 2.5 \\
\hline Triptan & 1,862 & 11.1 & 205 & 11.0 & 1.2 \\
\hline Ergotamine & 100 & 0.6 & 19 & 19.0 & 0.1 \\
\hline Total AMO (single class or multiclass) & - & - & 2,975 & 19.9 & 17.7 \\
\hline \multicolumn{6}{|c|}{$\begin{array}{l}\text { Abbreviations: } \mathrm{AMO}=\text { acute medication overuse; CaMEO = Chronic Migraine Epidemiology and Outcomes; NSAID = nonsteroidal anti-inflammatory drug; } \\
\text { OTC = over the counter; } \mathrm{R}_{\mathrm{x}}=\text { prescription. } \\
\text { a Denominator for this column is overall CaMEO analysis population }(\mathrm{N}=16,789) \text {. } \\
\text { b Denominator for this column is total number of medication users in each row. } \\
{ }^{c} \text { Combination analgesic includes survey responses of Excedrin, barbiturates, and Midrin. }\end{array}$} \\
\hline
\end{tabular}

month. The multiple-class AMO group included respondents who did not meet any single-class AMO criteria but met the criteria when multiple medication classes were considered: (1) use of 2 or more classes of medication (ergotamines, triptans, simple analgesics, and opioids) but not any single medication, for 10 or more days, and (2) use of 2 or more simple analgesics (acetaminophen, aspirin, NSAID, or other) cumulatively, but not any single medication, for $\geq 15$ days per month. Respondents could meet single-class AMO criteria for 1 or more classes of medication. Respondents meeting any criteria for AMO were categorized into the AMO subgroup, whereas those who failed to meet any criteria were categorized into the non-AMO group.

\section{Standard Protocol Approvals, Registrations, and Patient Consents}

The Albert Einstein College of Medicine Institutional Review Board approved the CaMEO Study and waived written informed consent for study volunteers, who had the right to accept or refuse participation in the survey. Data included in this analysis are from the CaMEO Study, which is registered on ClinicalTrials.gov (NCT01648530).

\section{Statistics}

Medication class use by AMO and non-AMO respondents, sociodemographics, headache frequency, depression, anxiety, migrainerelated disability, migraine interictal burden, $\mathrm{ED} / \mathrm{UC}$ use, and selfreported medical diagnosis of comorbidities were compared in a cross-sectional analysis. Medication class use was analyzed by counts reported in each medication class for each group.

The $\chi^{2}$ test was used for testing between-group differences in categorical variables. Continuous variables including MHDs and
PHQ-9, GAD-7, MIDAS, MIBS-4, and MSSS total scores were represented with medians and interquartile ranges (IQRs: $\mathrm{Q} 1$ and Q3). Between-group differences for continuous variables were assessed using the Mood median test between independent groups.

A series of nested multivariable binary logistic regression models was run with $\mathrm{AMO}$ vs non-AMO as the outcome. Covariates were entered in sequential blocks: sociodemographics, headache and respondent characteristics, psychiatric comorbidity, 6-month $\mathrm{ED} /$ UC use for headache or any reason, and preventive medication use. Separate models were run for any AMO, and AMO due to opioid use, triptan use, or NSAID use. Odds ratios (ORs) with 95\% confidence intervals (CIs) were calculated for each variable. After each block was entered, nonsignificant variables were trimmed from the model; significance level was $p<0.05$. No correction for multiple testing was applied. All analyses were performed using IBM SPSS Statistics Version 24.0 (IBM, Armonk, NY; 2011).

\section{Data Availability}

Additional data from the CaMEO Study (ClinicalTrials.gov Identifier: NCT01648530) may be requested at https://www. abbvie.com/our-science/clinical-trials/clinical-trials-dataand-information-sharing/data-and-information-sharing-withqualified-researchers.html.

\section{Results}

\section{Baseline Characteristics and Patterns of Acute Medication Use}

Of 16,789 total CaMEO respondents with migraine, 14,936 (89.0\%) reported using any acute medication to treat their 
Figure 1 Migraine-Related Burden, Disability, and Comorbidities by AMO Status (A) and by AMO Status and Headache Frequency (B)

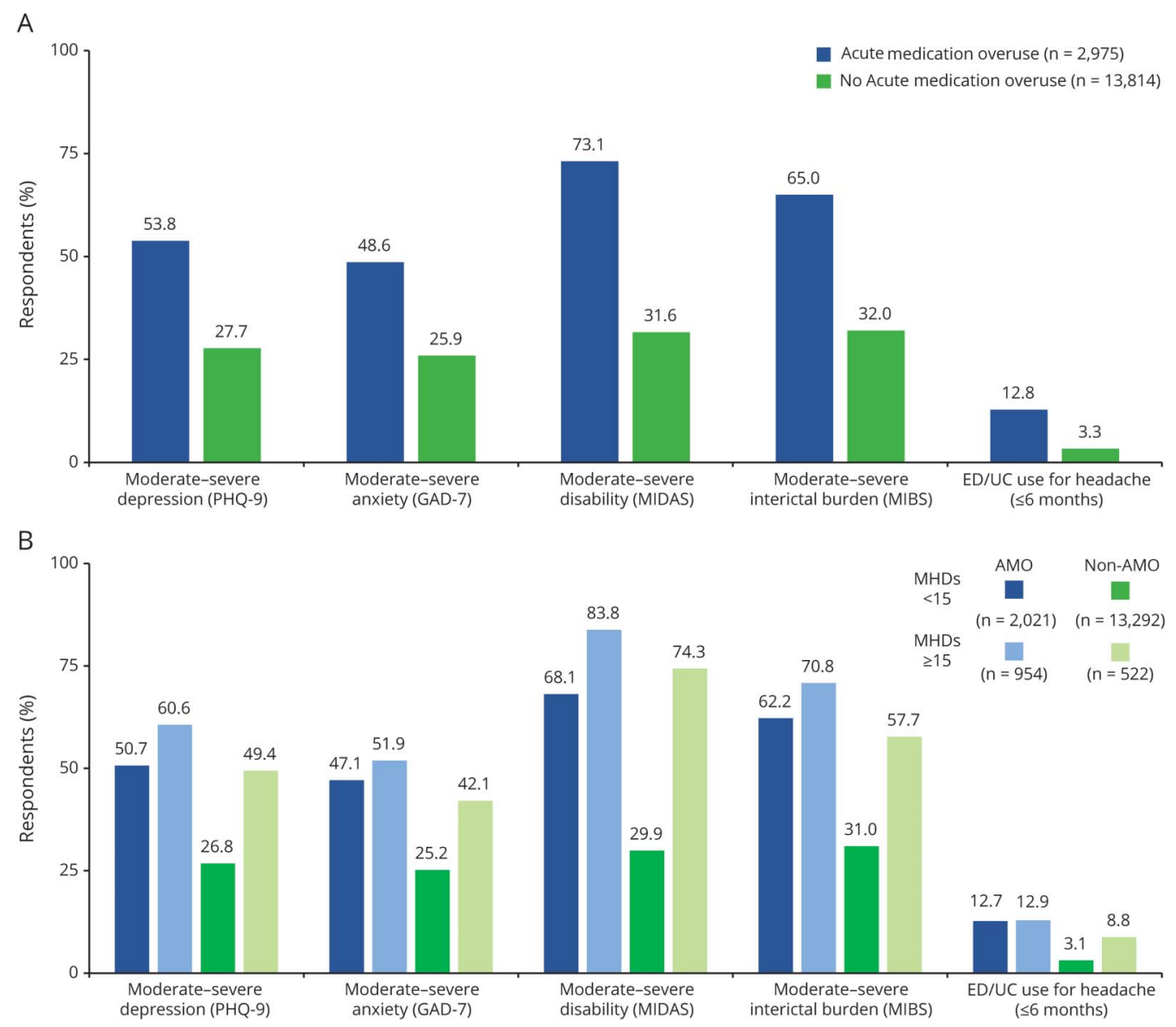

$p<0.001$ for all comparisons between the AMO and non-AMO groups; $\chi^{2}$ test. AMO = acute medication overuse; ED = emergency department; GAD-7 = Generalized Anxiety Disorder 7-Item Scale; MHD = monthly headache day; MIBS = Migraine Interictal Burden Scale; MIDAS = Migraine Disability Assessment; Mod = moderate; PHQ-9 = 9-Item Patient Health Questionnaire; UC = urgent care.

headaches. Use of any over-the-counter (OTC) medication for headache was reported by $14,279(85.0 \%)$ respondents, and use of any prescription medication was reported by 4,902 (29.2\%) respondents. A total of 4,245 (25.3\%) respondents reported use of both OTC and prescription medication.

\section{Baseline Characteristics by AMO Status}

Of 16,789 respondents with migraine, 2,975 (17.7\%) met the criteria for AMO, and 13,814 (82.3\%) did not have AMO (table 1). Respondents with AMO, compared with those who did not meet the AMO criteria, were more likely to be obese (BMI 30 $\mathrm{kg} / \mathrm{m}^{2}$ or greater: $42.2 \%$ vs $33.8 \%$; $p<0.001 \chi^{2}$ test); were less likely to have a 4 -year college degree $(39.8 \%$ vs $46.1 \%$; $p<$ $0.001 \chi^{2}$ test); had a higher median (IQR) number of MHDs (10.0 [4.3-16.7] vs 2.0 [1.0-4.7]; $p<0.001$; Mood median test); and were more likely to have $\geq 15 \mathrm{MHDs}$ ( $32.1 \%$ vs $3.8 \%$; $p<0.001 \chi^{2}$ test). A total of $67.9 \%$ of respondents that met the AMO criteria had $<15$ MHDs (table 1). Sociodemographic features and baseline characteristics subdivided by AMO status in individuals with $<15$ MHDs and in those with $\geq 15$ MHDs are shown in table e-1 (links.lww.com/CPJ/A253).

\section{Characterization of Single-Class AMO}

The majority (2,753 of 2,975 [92.5\%]) of respondents with AMO met the AMO criteria for at least 1 medication class, and $7.4 \%(222$ of 2,975$)$ met the criteria for multiple-class AMO but not single-class AMO. Among the respondents meeting singleclass AMO criteria, the overused medication classes were simple analgesics $(64.2 \%, 1,767 / 2,753)$, combination analgesics (34.1\%, 938/2,753), opioids (15.3\%, 422/2,753), triptans (7.4\%, 205/2,753), and ergotamines $(0.7 \%, 19 / 2,753)$. The frequency of reported medication use and overuse among the total CaMEO analysis sample and within those reporting any use of each medication class is shown in table 2. The proportion of respondents meeting the AMO criteria for each individual class of medication was similar between respondents reporting $<15$ MHDs and those reporting $\geq 15$ MHDs. Overall medication use across the AMO and MHD subgroups is shown in table e-2 (links.lww.com/CPJ/A254).

\section{Headache-Related Burden and Comorbidities}

Compared with respondents without AMO, respondents with AMO were more likely to have moderate to severe 
Table 3 Comparison of Comorbidities ( $>5 \%$ of Total) by AMO Status Within MHD Groups

Self-report medical diagnosed comorbidity

Cardiac disorders

High cholesterol

Hypertension

Irregular heart rhythms

Endocrine disorders

\begin{tabular}{l} 
Underactive thyroid \\
\hline Diabetes \\
\hline Gastrointestinal disorders
\end{tabular}

Irritable bowel/IBS

GERD

\begin{tabular}{|c|c|c|c|c|c|c|}
\hline Allergies & $689(45.5)$ & $3,686(36.2)$ & $<0.001$ & $372(51.2)$ & $195(50.6)$ & 0.851 \\
\hline Dermatitis/eczema & $160(10.6)$ & $972(9.5)$ & 0.208 & $90(12.4)$ & $36(9.4)$ & 0.128 \\
\hline \multicolumn{7}{|c|}{ Nervous system and psychiatric disorders } \\
\hline Vertigo/dizziness & $213(14.1)$ & $1,002(9.8)$ & $<0.001$ & $140(19.3)$ & $77(20.0)$ & 0.774 \\
\hline Sleep apnea & $163(10.8)$ & $686(6.7)$ & $<0.001$ & $87(12)$ & $43(11.2)$ & 0.688 \\
\hline Insomnia & $322(21.3)$ & $1,068(10.5)$ & $<0.001$ & $206(28.4)$ & $60(15.6)$ & $<0.001$ \\
\hline Anxiety & $572(37.8)$ & $2,435(23.9)$ & $<0.001$ & $320(44.1)$ & $149(38.7)$ & 0.084 \\
\hline Depression & $627(41.4)$ & $2,661(26.1)$ & $<0.001$ & $349(48.1)$ & $158(41.0)$ & 0.025 \\
\hline Panic disorder and panic attacks & $207(13.7)$ & $849(8.3)$ & $<0.001$ & $150(20.7)$ & $57(14.8)$ & 0.017 \\
\hline Nervousness & $147(9.7)$ & $518(5.1)$ & $<0.001$ & $92(12.7)$ & $32(8.3)$ & 0.028 \\
\hline \multicolumn{7}{|l|}{$\begin{array}{l}\text { Musculoskeletal and connective tissue } \\
\text { disorders }\end{array}$} \\
\hline Neck pain & $488(32.2)$ & $1,685(16.5)$ & $<0.001$ & $269(37.1)$ & $121(31.4)$ & 0.062 \\
\hline Chronic back pain & $436(28.8)$ & $1,522(14.9)$ & $<0.001$ & $233(32.1)$ & $95(24.7)$ & 0.010 \\
\hline Chronic pain & $196(12.9)$ & $475(4.7)$ & $<0.001$ & $146(20.1)$ & $55(14.3)$ & 0.016 \\
\hline Arthritis & $338(22.3)$ & $1,147(11.3)$ & $<0.001$ & $148(20.4)$ & $67(17.4)$ & 0.231 \\
\hline Osteoarthritis & $203(13.4)$ & $851(8.4)$ & $<0.001$ & $112(15.4)$ & $41(10.6)$ & 0.028 \\
\hline TMD & $149(9.8)$ & $642(6.3)$ & $<0.001$ & $101(13.9)$ & $53(13.8)$ & 0.947 \\
\hline \multicolumn{7}{|l|}{$\begin{array}{l}\text { Respiratory, thoracic, and mediastinal } \\
\text { disorders }\end{array}$} \\
\hline Asthma & $365(24.1)$ & $1,823(17.9)$ & $<0.001$ & $180(24.8)$ & $100(26.0)$ & 0.666 \\
\hline Chronic bronchitis & $156(10.3)$ & $486(4.8)$ & $<0.001$ & $85(11.7)$ & $38(9.9)$ & 0.353 \\
\hline Sinusitis & $878(58)$ & 4,659 (45.7) & $<0.001$ & $432(59.5)$ & $221(57.4)$ & 0.498 \\
\hline \multicolumn{7}{|l|}{ Reproductive system } \\
\hline PMS $^{\mathbf{b}}$ & $210(13.9)$ & $978(9.6)$ & $<0.001$ & $123(16.9)$ & $54(14)$ & 0.206 \\
\hline
\end{tabular}

$<15$ MHDs

AMO $(n=2021) \quad$ No AMO $(n=13,292) \quad p$ Value $^{a} \quad$ AMO $(n=954) \quad$ No AMO $(n=522) \quad p$ Value

\begin{tabular}{llllll}
$431(28.5)$ & $2,124(20.9)$ & $<0.001$ & $221(30.4)$ & $86(22.3)$ & 0.004 \\
\hline $364(24.0)$ & $1,868(18.3)$ & $<0.001$ & $197(27.1)$ & $89(23.1)$ & 0.145 \\
\hline $167(11.0)$ & $845(8.3)$ & $<0.001$ & $91(12.5)$ & $27(7.0)$ & 0.004
\end{tabular}

$160(10.6) \quad 809(7.9)$

$674(6.6)$

$0.001 \quad 89(12.3)$

31 (8.1)

0.032

$168(11.1)$

$<0.001 \quad 69(9.5)$

$38(9.9)$

0.844

$185(12.4)$

$\begin{array}{ll}185(12.4) & 830(8.3) \\ 324(21.4) & 1,347(13.2)\end{array}$

$<0.001 \quad 130(18.3)$

$<0.001 \quad 178(24.5)$

50 (13.1)

93 (24.2)

0.027

324 (21.4) $\quad$ 1,347 (13.2)

$<0.001 \quad 178(24.5)$

0.894

\section{Immune system disorders}


Table 3 Comparison of Comorbidities ( $>5 \%$ of Total) by AMO Status Within MHD Groups (continued)

\begin{tabular}{|c|c|c|c|c|c|c|}
\hline \multirow{2}{*}{$\begin{array}{l}\text { Self-report medical diagnosed } \\
\text { comorbidity }\end{array}$} & \multicolumn{3}{|l|}{$<15$ MHDs } & \multicolumn{3}{|l|}{$\geq 15$ MHDs } \\
\hline & $\operatorname{AMO}(n=2021)$ & No AMO $(n=13,292)$ & $p$ Value $^{a}$ & $\mathrm{AMO}(\mathrm{n}=954)$ & No AMO $(n=522)$ & $p$ Value $^{\mathrm{a}}$ \\
\hline Endometriosis $^{\mathbf{b}}$ & $105(9.2)$ & $469(6.2)$ & $<0.001$ & 69 (11.7) & $25(7.9)$ & 0.079 \\
\hline
\end{tabular}

Abbreviations: AMO = acute medication overuse; GERD = gastroesophageal reflux disease; HCP = health care professional; IBS = irritable bowel syndrome; $\mathrm{MHD}=$ monthly headache day; PMS = premenstrual syndrome; TMD = temporomandibular joint dysfunction.

All data are $n(\%)$.

${ }^{a}$ Comparison between the AMO and non-AMO groups in respective headache frequency category with the $\chi^{2}$ test.

${ }^{\mathrm{b}}$ Calculations are based on the total sample number, not female respondents only.

depression (PHQ-9; $p<0.001 ; \chi^{2}$ test), moderate to severe anxiety (GAD-7; $p<0.001 ; \chi^{2}$ test), moderate to severe interictal burden (MIBS; $p<0.001 ; \chi^{2}$ test), moderate to severe headache-related disability (MIDAS; $p<0.001 ; \chi^{2}$ test), and a higher incidence of ED/UC use for headache within the past 6 months $\left(p<0.001 ; \chi^{2}\right.$ test) (figure 1A). To evaluate the independent impact of both AMO status and headache frequency, the AMO and non-AMO groups were subdivided into those with $<15$ MHDs and those with $\geq 15$ MHDs (figure 1B). AMO was consistently associated with a substantial increase in depression, anxiety, headache-related disability, migraine interictal burden, and $\mathrm{ED} / \mathrm{UC}$ use for headache across both MHD subgroups.

Respondents with $\geq 15$ MHDs had higher rates of depression, anxiety, headache-related disability, migraine interictal burden, and ED/UC use for headache compared with those reporting $<15$ MHDs in both the AMO and non-AMO subgroups. The observed impact of $\geq 15 \mathrm{MHDs}$ was greater in those without AMO than in those with AMO.

Within both MHD subgroups, the percentage of respondents with self-reported medical diagnosed comorbidities tended to be greater in those with AMO compared with those without AMO (table 3). Within the <15 MHDs subgroup, the relative frequency of musculoskeletal and connective tissue disorders including neck pain, chronic back pain, arthritis, and chronic pain showed some of the largest differences between AMO groups, being approximately 2-3 times more frequent in those with AMO. Within the $\geq 15$ MHDs subgroup, the AMO-associated differences tended to be smaller than in the $<15$ MHDs subgroup.

\section{Factors Associated With AMO Based on Multivariable Binary Logistic Regression Models}

To identify possible predictors of AMO status, a series of nested multivariable binary logistic models was run with nonsignificant variables removed at each step; the fully adjusted models for AMO and select acute medications are shown in table 4 (each individual nested model is shown in tables e-3-e-6, links.lww.com/CPJ/A255, links.lww.com/ CPJ/A256, links.lww.com/CPJ/A257, and links.lww.com/ $\mathrm{CPJ} / \mathrm{A} 258)$. Consistent factors identified as significant predictors of $\mathrm{AMO}$ in the fully adjusted models for all medication classes evaluated (any AMO, triptans, opioids, and NSAIDs) included $\geq 15$ MHDs, moderate to severe disability (MIDAS), severe MIBS score, use of preventive medication, and $\mathrm{ED} / \mathrm{UC}$ visits for headache within the previous 6 months. Overusing opioids for the acute treatment of headache was associated with a lower likelihood of employment (OR [95\% CI $]=0.61[0.47-0.79])$. Overusing triptans for the acute treatment of headache was associated with a greater likelihood of diagnosis of migraine by a phy$\operatorname{sician}(\mathrm{OR}[95 \% \mathrm{CI}]=4.11[2.5-6.75])$.

\section{Discussion}

Approximately $17.7 \%$ of the CaMEO Study respondents with migraine met the criteria for AMO. Opioids and combination analgesics were the most likely medications to be overused by respondents reporting use of those medications. Overall, respondents with $\mathrm{AMO}$ had greater headache-related disability, anxiety, depression, and ED/UC use for headache than those without AMO. Respondents with both AMO and $\geq 15$ MHDs showed the highest total burden, but there was also a substantial negative impact of AMO in those with $<15$ MHDs. The differences in the relative frequency of selfreported medical diagnosed comorbidities between AMO and non-AMO respondents were greatest in the $<15$ MHDs subgroups, with many pain-related comorbidities exhibiting the largest differences in the AMO subgroup compared with the non-AMO subgroup. This greater relative frequency of pain-related comorbidities may contribute to the high level of medication use in those with $<15$ MHDs. Higher rates of anxiety may also contribute to AMO in that group. Finally, results of the nested multivariable binary logistic models show positive relationships between AMO status and migraine-related disability, interictal burden, and ED/UC use for headache.

The findings of this study are consistent with other studies evaluating AMO in people with migraine. Results from the Migraine in America Symptoms and Treatment study showed that survey respondents with AMO were more likely to be obese, have allodynia, have depression and/or anxiety, and report $\geq 15$ headache days per month. ${ }^{17}$ European studies demonstrated that female sex, headache frequency, comorbid pain conditions, comorbid psychiatric conditions, and type of overused medication are associated with 
Table 4 Factors Associated With Risk of AMO Based on Nested Multivariable Binary Logistic Regression Models: Comparison of Final Models With Removal of Nonsignificant Covariates Except Age and Sex

\begin{tabular}{|c|c|c|c|c|}
\hline \multirow[b]{2}{*}{ Variable } & \multicolumn{4}{|c|}{ Odds ratio $(95 \% \mathrm{Cl})$ for multiple outcomes } \\
\hline & AMO (any) & Triptan overuse $\geq 10 \mathrm{~d}$ & Opioid overuse $\geq 10 \mathrm{~d}$ & NSAID overuse $\geq 15 \mathrm{~d}$ \\
\hline Age & $1.15(1.13-1.17)$ & $1.08(1.02-1.15)$ & $1.13(1.08-1.19)$ & $1.11(1.08-1.14)$ \\
\hline Female & $0.9(0.80-1.01)$ & $0.96(0.66-1.39)$ & $0.67(0.50-0.89)$ & $1.00(0.86-1.17)$ \\
\hline Employed & - & - & $0.61(0.47-0.79)$ & - \\
\hline Migraine diagnosis by physician & $1.33(1.20-1.48)$ & $4.11(2.50-6.75)$ & - & - \\
\hline MIDAS $\geq 11$ (moderate-severe disability) & $2.05(1.83-2.29)$ & $2.31(1.44-3.69)$ & $1.89(1.32-2.71)$ & $1.67(1.42-1.96)$ \\
\hline Allodynia presence (ASC $\geq 3$ ) & - & - & $1.93(1.44-2.60)$ & - \\
\hline \multicolumn{5}{|l|}{ MHDs $^{\mathrm{a}}$} \\
\hline $5-9$ & $2.65(2.34-3.00)$ & $3.43(2.07-5.68)$ & $1.71(1.17-2.49)$ & $2.47(2.06-2.96)$ \\
\hline $10-14$ & $5.99(5.17-6.95)$ & $6.55(3.89-11.02)$ & $2.87(1.93-4.25)$ & $4.81(3.94-5.88)$ \\
\hline$\geq 15$ & $12.37(10.72-14.28)$ & $6.28(3.83-10.31)$ & $3.43(2.40-4.91)$ & $7.53(6.29-9.03)$ \\
\hline HAs currently managed by a specialist ${ }^{\mathrm{b}}$ & $1.29(1.07-1.56)$ & $1.66(1.17-2.37)$ & $2.36(1.70-3.27)$ & - \\
\hline \multicolumn{5}{|l|}{ MIBS $^{c}$} \\
\hline Mild (1-2) & $1.28(1.10-1.49)$ & $2.73(1.34-5.58)$ & $1.25(0.71-2.20)$ & $1.17(0.95-1.44)^{d}$ \\
\hline Moderate (3-4) & $1.57(1.36-1.83)$ & $3.68(1.87-7.23)$ & $2.28(1.39-3.74)$ & $1.30(1.06-1.60)$ \\
\hline Severe $(\geq 5)$ & $2.16(1.90-2.46)$ & $4.05(2.16-7.60)$ & $3.32(2.14-5.17)$ & $1.57(1.31-1.87)$ \\
\hline Depression (PHQ-9 $\geq 10$ ) & $1.29(1.14-1.46)$ & - & $1.68(1.27-2.23)$ & $1.32(1.12-1.56)$ \\
\hline Anxiety (GAD-7 $\geq 10$ ) & $1.52(1.34-1.72)$ & - & - & $1.57(1.34-1.84)$ \\
\hline ED/UC use in past 6 mo for any reason & - & - & $1.69(1.22-2.33)$ & $1.16(0.94-1.44)^{d}$ \\
\hline ED/UC use in past 6 mo for headache & $1.72(1.44-2.05)$ & $1.89(1.31-2.71)$ & $2.00(1.36-2.94)$ & - \\
\hline Use of preventive medication & $2.03(1.71-2.41)$ & $5.12(3.71-7.07)$ & $1.84(1.34-2.52)$ & $2.22(1.84-2.66)$ \\
\hline
\end{tabular}

Abbreviations: $\mathrm{AMO}=$ acute medication overuse; $\mathrm{AMOH}=$ acute medication overuse headache; $\mathrm{ASC}=$ Allodynia Symptom Checklist; $\mathrm{Cl}=$ confidence interval; $\mathrm{ED}=$ emergency department; GAD-7 = Generalized Anxiety Disorder 7-Item Scale; MHDs = monthly headache days; MIBS = Migraine Interictal Burden Scale; MIDAS = Migraine Disability Assessment; NSAID = nonsteroidal anti-inflammatory drug; PHQ-9 = 9-item Patient Health Questionnaire; UC = urgent care. Only variables that were included in at least 1 final model are shown; race, income, and college degree were not included in any of the final models. "—" indicates variable trimmed from the model because of nonsignificance.

${ }^{a}$ The reference group was 0-4 MHDs.

${ }^{\mathrm{b}}$ Specialist was defined as a neurologist, pain, or headache specialist.

${ }^{c}$ Reference is no interictal burden (MIBS score of 0 ).

${ }^{d}$ Variable is nonsignificant in final model.

AMO. ${ }^{18-21}$ Migraine is associated with multiple comorbidities, which could contribute to increased medication use. ${ }^{22}$ The many pain comorbidities of migraine could contribute to increased use of analgesics. ${ }^{23} \mathrm{~A}$ cross-sectional, schoolbased study found an overall prevalence of probable $\mathrm{MOH}$ of $0.9 \%$, with similar prevalence in boys and girls. ${ }^{24}$ An overall prevalence of probable $\mathrm{MOH}$ of $2.0 \%$ was reported in a Saudi Arabian study, with a greater occurrence in females and participants $46-55$ years of age. ${ }^{25}$ Additional studies in Asia found that headache disorders (including $\mathrm{MOH}$ ) are associated with a substantial overall burden, with unmet treatment needs including high rates of over-the-counter medication use. ${ }^{26,27}$ Taken together, the results of these studies show a pronounced disease-related burden in those who overuse acute medications for migraine.
AMO is associated with the risk of migraine disease progression from episodic migraine (EM) to chronic migraine (CM). ${ }^{9,13,28,29}$ In the AMPP study, triptan overuse alone was associated with risk of disease progression from EM to CM depending on the baseline frequency of MHDs; however, triptan use in combination with NSAIDs was not associated with an increased risk of progression, and NSAID use may be protective of progressing from EM to $\mathrm{CM}$ depending on MHDs. ${ }^{13,28,30}$ In addition, opioids and barbiturate analgesics are associated with dose-dependent increased risk of $\mathrm{CM}$ onset across a range of frequencies. ${ }^{8,13,31}$ Although the relationship between medication use and disease progression is not straightforward across all acute medication classes, the suboptimal treatment of migraine attacks is a risk factor for progression. 
The true burden related to $\mathrm{AMO} / \mathrm{MOH}$ may be underestimated in practice, as diagnostic criteria for $\mathrm{MOH}$ require 15 MHDs. ${ }^{11}$ The analyses reported herein demonstrate that $68 \%$ of participants with AMO had $<15$ MHDs, and these respondents demonstrated substantial burden. In addition, $49 \%$ of respondents who reported AMO also reported $<10$ MHDs, suggesting that these respondents are taking migraine medication on days when they do not have a headache, or taking multiple different acute medications to treat each headache, thus meeting the criteria for AMO with combination use of multiple classes. In addition, some people with migraine may take acute medication preemptively to try to avoid onset of a migraine attack and/or to manage associated anxiety. This practice would be counted as a medication day, but not as a headache day, leading to respondents exhibiting AMO but failing to meet ICHDdefined criteria for $\mathrm{MOH} .{ }^{11}$ Health care professionals should review the frequency of acute medication use in all patients with migraine, regardless of the monthly headache frequency and especially in those with comorbid pain conditions.

Because AMO is common and associated with high disease burden in people with migraine, it is an important target for prevention and treatment. Approaches for avoiding and treating $\mathrm{AMO}$ and $\mathrm{MOH}$ include using effective acute treatments, using patient and clinician education about limiting intake of acute medications, and initiating and optimizing pharmacologic and nonpharmacologic preventive treatments. $^{32}$ Nonpharmacologic approaches include cognitive behavioral therapy that is specifically focused on AMO treatment and reducing the factors that lead to overuse of the acute medication. ${ }^{20,33}$ Improved efficacy and outcomes for elimination of AMO are achieved when behavioral therapies are included as part of treatment. ${ }^{34}$

Although most acute treatments can cause AMO, emerging evidence suggests that gepants, a novel class of small-molecule calcitonin gene-related peptide (CGRP) receptor antagonists, may not. In a preclinical model of $\mathrm{MOH}$, repeated administration of pharmacologically active doses of ubrogepant (a CGRP receptor antagonist) did not produce $\mathrm{MOH}$-like latent sensitization in female rats. ${ }^{35}$ In long-term safety studies, frequent use of gepants over the course of a year was associated with a reduction and not an increase in monthly migraine days. ${ }^{36}$ Unlike most oral acute treatments for migraine for which an $\mathrm{MOH}$ warning is required, the prescribing information for the US Food and Drug Administration-approved gepants (ubrogepant and rimegepant) does not include a warning for $\mathrm{MOH}$ as is required for most oral acute treatments for migraine. ${ }^{37-39}$ Although it is promising that the CGRP receptor antagonists might not be associated with $\mathrm{AMO}$, more research is needed to fully understand the relationship between their use and $\mathrm{MOH}$, especially in individuals with a high frequency of migraine days. ${ }^{40}$

Strengths of this study include the large sample size $(16,789$ CaMEO respondents with migraine) and the ability to collect detailed medication use information across a spectrum of individuals with varying migraine frequency. However, as this was a cross-sectional study, the data can only report the frequency of medication use and headache frequency separately; causality cannot be determined. The data collected are self-reported by survey respondents who met the AMO criteria. Participation bias could influence the results. Finally, due to the design of the questionnaire, we could not assess the reason for each reported medication use by respondents and could not differentiate between acute medication use to treat a headache/migraine or preemptive use in anticipation of a headache.

Respondents with AMO had more headache-related disability, anxiety, depression, and ED/UC use for headache than those without $\mathrm{AMO}$ in both MHD frequency groups (i.e., < $15 \mathrm{MHD}$ and $\geq 15$ MHDs). These same factors were identified as showing a significant relationship with AMO via multivariable binary logistic regression analysis. Use of comprehensive migraine treatment plans that include improved acute treatment options as well as considering guideline-based preventive treatments, including both pharmacologic and nonpharmacologic modalities, combined with appropriate education may help to reduce the relative frequency of AMO and the associated burden from possible $\mathrm{MOH}$.

\section{Acknowledgment}

Writing and editorial assistance was provided to the authors by Peloton Advantage, LLC, an OPEN Health company, Parsippany, NJ. The opinions expressed in this article are those of the authors. The authors received no honoraria/fees or other form of financial support related to the development of this article.

\section{Study Funding}

This study was sponsored by Allergan (prior to its acquisition by AbbVie).

\section{Disclosure}

T.J. Schwedt has served as a consultant for AbbVie, Alder, Amgen, ATI, Aural Analytics, Avanir, Biohaven, Cipla, Click Therapeutics, Dr. Reddy's Laboratories, Eli Lilly, Equinox, Ipsen Bioscience, Lundbeck, Nocira, Novartis, Promius Pharma, Salvia, Second Opinion, Teva, Xoc, and Weber and Weber; he holds stock options in Aural Analytics, Nocira, and Second Opinion and has received research funding from Amgen. D.C. Buse has received grant support and honoraria from AbbVie, Amgen, Avanir, Biohaven, Dr. Reddy's/ Promius, Eli Lilly and Company, and Teva and for work on the editorial board of Current Pain and Headache Reports. C.E. Argoff has served as a consultant for Lilly, Novartis, and Teva and has received honoraria from AbbVie, Amgen, Lilly, Novartis, Teva, and Theranica; he has received royalties from Elsevier for Pain Management Secrets and Raj's Practical Management of Pain. M.L. Reed is Managing Director of Vedanta Research, which has received research funding from AbbVie, Amgen, Dr. Reddy's Laboratories, Eli Lilly, GlaxoSmithKline, Merck \& Co., Inc., and the National 
Headache Foundation. Vedanta Research has received funding directly from AbbVie for work on the CaMEO Study. K.M. Fanning is an employee of Vedanta Research, which has received research funding from AbbVie, Amgen, Dr. Reddy's Laboratories, Eli Lilly, GlaxoSmithKline, Merck \& Co., Inc., and the National Headache Foundation. Vedanta has received funding directly from AbbVie for work on the CaMEO Study. C.R. Hussar is an employee of Peloton Advantage, LLC, an OPEN Health company. A.M. Adams is an employee of AbbVie and may hold AbbVie stock. R.B. Lipton serves on the editorial boards of Neurology and Cephalalgia and as senior advisor to Headache; he receives research support from the $\mathrm{NIH}$; he also receives support from the Migraine Research Foundation and the National Headache Foundation; he has reviewed for the National Institute of Aging and the National Institute of Neurological Disorders and Stroke; serves as consultant, advisory board member, or has received honoraria from AbbVie, Alder, Amgen, Axsome, Dr. Reddy's, electroCore, Eli Lilly, eNeura Therapeutics, GlaxoSmithKline, Merck, Novartis, Teva, and Vedanta; he receives royalties from Wolff's Headache, 8th edition (Oxford University Press, 2009) and Informa; and he holds stock options in Biohaven and eNeura Therapeutics. Full disclosure form information provided by the authors is available with the full text of this article at Neurology.org/cp.

\section{Publication History}

Received by Neurology: Clinical Practice July 30, 2020. Accepted in final form January 4, 2021.

Appendix Authors

\begin{tabular}{lll}
\hline Name & Location & Contribution \\
\hline $\begin{array}{l}\text { Todd J. Schwedt, } \\
\text { MD }\end{array}$ & Mayo Clinic, Phoenix, AZ & $\begin{array}{l}\text { Interpreted the data; } \\
\text { drafted the manuscript for } \\
\end{array}$ \\
& $\begin{array}{l}\text { intellectual content; and } \\
\text { revised the manuscript for } \\
\text { intellectual content }\end{array}$
\end{tabular}

Dawn C. Buse, Albert Einstein College of Designed and

PhD Medicine, Bronx, NY conceptualized the study; major role in the acquisition of data; interpreted the data; drafted the manuscript for intellectual content; and revised the manuscript for intellectual content

Charles E. Argoff, Albany Medical Center, Interpreted the data; MD Albany, NY drafted the manuscript for intellectual content; and revised the manuscript for intellectual content

Michael L. Reed, Vedanta Research, Chapel Designed and PhD Hill, NC conceptualized the study major role in the enrollment of patients and the acquisition of data; interpreted the data; drafted the manuscript for intellectual content; and revised the manuscript for intellectual content
Appendix (continued)

\begin{tabular}{|c|c|c|}
\hline Name & Location & Contribution \\
\hline $\begin{array}{l}\text { Kristina M. } \\
\text { Fanning, PhD }\end{array}$ & $\begin{array}{l}\text { Vedanta Research, Chapel } \\
\text { Hill, NC }\end{array}$ & $\begin{array}{l}\text { Interpreted the data; } \\
\text { drafted the manuscript for } \\
\text { intellectual content; and } \\
\text { revised the manuscript for } \\
\text { intellectual content }\end{array}$ \\
\hline $\begin{array}{l}\text { Cory R. Hussar, } \\
\text { PhD }\end{array}$ & $\begin{array}{l}\text { Peloton Advantage, LLC, } \\
\text { an OPEN Health company, } \\
\text { Parsippany, NJ }\end{array}$ & $\begin{array}{l}\text { Interpreted the data; } \\
\text { drafted the manuscript for } \\
\text { intellectual content; and } \\
\text { revised the manuscript for } \\
\text { intellectual content }\end{array}$ \\
\hline $\begin{array}{l}\text { Aubrey Manack } \\
\text { Adams, PhD }\end{array}$ & AbbVie, Irvine, CA & $\begin{array}{l}\text { Designed and } \\
\text { conceptualized the study; } \\
\text { major role in the } \\
\text { acquisition of data; } \\
\text { interpreted the data; } \\
\text { drafted the manuscript for } \\
\text { intellectual content; and } \\
\text { revised the manuscript for } \\
\text { intellectual content }\end{array}$ \\
\hline $\begin{array}{l}\text { Richard B. } \\
\text { Lipton, MD }\end{array}$ & $\begin{array}{l}\text { Albert Einstein College of } \\
\text { Medicine, Bronx, NY }\end{array}$ & $\begin{array}{l}\text { Designed and } \\
\text { conceptualized the study; } \\
\text { major role in the } \\
\text { acquisition of data; } \\
\text { interpreted the data; } \\
\text { contributed to data } \\
\text { analysis; drafted the } \\
\text { manuscript for intellectual } \\
\text { content; and revised the } \\
\text { manuscript for intellectual } \\
\text { content }\end{array}$ \\
\hline
\end{tabular}

\section{References}

1. Burch R, Rizzoli P, Loder E. The prevalence and impact of migraine and severe headache in the United States: figures and trends from government health studies. Headache 2018;58:496-505.

2. Goadsby PJ, Lipton RB, Ferrari MD. Migraine-current understanding and treatment. N Engl J Med 2002;346:257-270.

3. Pietrobon D, Moskowitz MA. Pathophysiology of migraine. Annu Rev Physiol 2013; 75:365-391.

4. Silberstein SD. Practice parameter: evidence-based guidelines for migraine headache (an evidence-based review): report of the Quality Standards Subcommittee of the American Academy of Neurology. Neurology 2000;55:754-762.

5. Holland S, Fanning KM, Serrano D, Buse DC, Reed ML, Lipton RB. Rates and reasons for discontinuation of triptans and opioids in episodic migraine: results from the American Migraine Prevalence and Prevention (AMPP) study. J Neurol Sci 2013; 326:10-17.

6. Messali AJ, Yang M, Gillard P, et al. Treatment persistence and switching in triptan users: a systematic literature review. Headache 2014;54:1120-1130.

7. Wells RE, Markowitz SY, Baron EP, et al. Identifying the factors underlying discontinuation of triptans. Headache 2014;54:278-289.

8. Lipton RB, Fanning KM, Serrano D, Reed ML, Cady R, Buse DC. Ineffective acute treatment of episodic migraine is associated with new-onset chronic migraine. Neurology 2015;84:688-695.

9. Buse DC, Greisman JD, Baigi K, Lipton RB. Migraine progression: a systematic review. Headache 2019;59:306-338.

10. Serrano D, Kori S, Papapetropoulos S, et al. Does adding acute treatment improve migraine outcomes in patients on triptans? Results of the America Migraine Prevalence \& Prevention (AMPP) Study [abstract]. Presented at: Annual Scientific Meeting of the American Headache Society; June 21-24, 2012; Los Anegles, CA.

11. Headache Classification Committee of the International Headache Society. The International Classification of Headache Disorders, 3rd edition. Cephalalgia 2018;38: $1-211$.

12. Lampl C, Thomas H, Stovner LJ, et al. Interictal burden attributable to episodic headache: findings from the Eurolight project. J Headache Pain 2016;17:9.

13. Bigal ME, Serrano D, Buse D, Scher A, Stewart WF, Lipton RB. Acute migraine medications and evolution from episodic to chronic migraine: a longitudinal population-based study. Headache 2008;48:1157-1168.

14. Manack Adams A, Serrano D, Buse DC, et al. The impact of chronic migraine: the Chronic Migraine Epidemiology and Outcomes (CaMEO) Study methods and baseline results. Cephalalgia 2015;35:563-578.

15. Headache Classification Subcommittee of the International Headache Society. The International Classification of Headache Disorders, 2nd ed. Cephalalgia 2004; 24(suppl 1):9-160. 
16. Headache Classification Committee of the International Headache Society. The International Classification of Headache Disorders, 3rd edition (beta version). Cephalalgia 2013;33:629-808.

17. Schwedt TJ, Alam A, Reed ML, et al. Factors associated with acute medication overuse in people with migraine: results from the 2017 migraine in America symptoms and treatment (MAST) study. J Headache Pain 2018;19:38.

18. Hagen K, Linde M, Steiner TJ, Stovner LJ, Zwart JA. Risk factors for medicationoveruse headache: an 11-year follow-up study. The Nord-Trondelag Health Studies. Pain 2012;153:56-61.

19. Katsarava Z, Muessig M, Dzagnidze A, Fritsche G, Diener HC, Limmroth V. Medication overuse headache: rates and predictors for relapse in a 4-year prospective study. Cephalalgia 2005;25:12-15.

20. Diener HC, Holle D, Solbach K, Gaul C. Medication-overuse headache: risk factors, pathophysiology and management. Nat Rev Neurol 2016;12:575-583.

21. Lampl C, Thomas H, Tassorelli C, et al. Headache, depression and anxiety: associations in the Eurolight project. J Headache Pain 2016;17:59.

22. Korolainen MA, Tuominen S, Kurki S, et al. Burden of migraine in Finland: multimorbidity and phenotypic disease networks in occupational healthcare. J Headache Pain 2020;21:8.

23. Scher AI, Buse DC, Fanning KM, et al. Comorbid pain and migraine chronicity: the chronic migraine epidemiology and outcomes study. Neurology 2017;89:461-468.

24. Philipp J, Zeiler M, Wöber C, et al. Prevalence and burden of headache in children and adolescents in Austria - a nationwide study in a representative sample of pupils aged 10-18 years. J Headache Pain 2019;20:101.

25. Al Jumah M, Al Khathaami AM, Kojan S, Hussain M, Thomas H, Steiner TJ. The prevalence of primary headache disorders in Saudi Arabia: a cross-sectional population-based study. J Headache Pain 2020;21:11.

26. Takeshima T, Wan Q, Zhang Y, et al. Prevalence, burden, and clinical management of migraine in China, Japan, and South Korea: a comprehensive review of the literature. J Headache Pain 2019;20:111.

27. Yao C, Wang Y, Wang L, et al. Burden of headache disorders in China, 1990-2017: findings from the Global Burden of Disease Study 2017. J Headache Pain 2019;20:102.
28. Raggi A, Schiavolin S, Leonardi M, et al. Chronic migraine with medication overuse association between disability and quality of life measures, and impact of disease on patients' lives. J Neurol Sci 2015;348:60-66.

29. Xu J, Kong F, Buse DC. Predictors of episodic migraine transformation to chronic migraine: a systematic review and meta-analysis of observational cohort studies. Cephalalgia 2020;40:503-516

30. Lipton RB, Serrano D, Nicholson RA, Buse DC, Runken MC, Reed ML. Impact of NSAID and triptan use on developing chronic migraine: results from the American Migraine Prevalence and Prevention (AMPP) study. Headache 2013;53:1548-1563.

31. Bigal ME, Lipton RB. Modifiable risk factors for migraine progression. Headache 2006;46:1334-1343.

32. Vandenbussche $\mathrm{N}$, Laterza $\mathrm{D}$, Lisicki $\mathrm{M}$, et al. Medication-overuse headache: a widely recognized entity amidst ongoing debate. J Headache Pain 2018;19:50.

33. Evers S, Jensen R. Treatment of medication overuse headache-guideline of the EFNS headache panel. Eur J Neurol 2011;18:1115-1121.

34. Grazzi L, Usai S, Prunesti A, Bussone G, Andrasik F. Behavioral plus pharmacological treatment versus pharmacological treatment only for chronic migraine with medication overuse after day-hospital withdrawal. Neurol Sci 2009;30(suppl 1) S117-S119.

35. Navratilova E, Behravesh S, Oyarzo J, Dodick DW, Banerjee P, Porreca F. Ubrogepant does not induce latent sensitization in a preclinical model of medication overuse headache. Cephalalgia 2020;40:892-902.

36. Lipton RB, Berman G, Kudrow D, et al. Long-term, open-label safety study of rimegepant $75 \mathrm{mg}$ for the treatment of migraine (study 201): interim analysis of safety and exploratory efficacy [abstract P235LB]. Headache 2019;59(suppl 1):175.

37. Ubrelvy [package insert]. Madison, NJ: Allergan USA, Inc.; 2020.

38. Imitrex [package insert]. Research Triangle Park, NC: GlaxoSmithKline; 2017.

39. Nurtec ODT [package insert]. New Haven, CT: Biohaven Pharmaceuticals, Inc.; 2020.

40. van Hoogstraten WS, MaassenVanDenBrink A. The need for new acutely acting antimigraine drugs: moving safely outside acute medication overuse. J Headache Pain 2019;20:54.

\section{Practical Implications}

Neurology ${ }^{\oplus}$ Clinical Practice is committed to providing clinical insights helpful to neurologists in everyday practice. Each Full Case includes a "Practical Implications" statement, a pearl of wisdom for the practicing clinician. 


\title{
Neurology ${ }^{\circ}$ Clinical Practice
}

\author{
Medication Overuse and Headache Burden: Results From the CaMEO Study \\ Todd J. Schwedt, Dawn C. Buse, Charles E. Argoff, et al. \\ Neurol Clin Pract 2021;11;216-226 Published Online before print January 25, 2021 \\ DOI 10.1212/CPJ.0000000000001037
}

This information is current as of January 25, 2021

\begin{abstract}
Updated Information \&
Services

including high resolution figures, can be found at:

http://cp.neurology.org/content/11/3/216.full.html

References

This article cites 36 articles, 2 of which you can access for free at: http://cp.neurology.org/content/11/3/216.full.html\#\#ref-list-1

Citations

This article has been cited by 1 HighWire-hosted articles:

http://cp.neurology.org/content/11/3/216.full.html\#\#otherarticles

Subspecialty Collections

This article, along with others on similar topics, appears in the following collection(s):

Clinical trials Observational study (Cohort, Case control)

http://cp.neurology.org//cgi/collection/clinical_trials_observational_stu dy_cohort_case_control

Migraine

http://cp.neurology.org//cgi/collection/migraine

Prevalence studies

http://cp.neurology.org//cgi/collection/prevalence_studies

Risk factors in epidemiology

http://cp.neurology.org//cgi/collection/risk_factors_in_epidemiology

Secondary headache disorders

http://cp.neurology.org//cgi/collection/secondary_headache_disorders

Permissions \& Licensing

Information about reproducing this article in parts (figures,tables) or in its entirety can be found online at:

http://cp.neurology.org/misc/about.xhtml\#permissions

Reprints

Information about ordering reprints can be found online:

http://cp.neurology.org/misc/addir.xhtml\#reprintsus
\end{abstract}

Neurol Clin Pract is an official journal of the American Academy of Neurology. Published continuously since 2011, it is now a bimonthly with 6 issues per year. Copyright Copyright $\odot 2021$ The Author(s). Published by Wolters Kluwer Health, Inc. on behalf of the American Academy of Neurology.. All rights reserved. Print ISSN: 2163-0402. Online ISSN: 2163-0933.

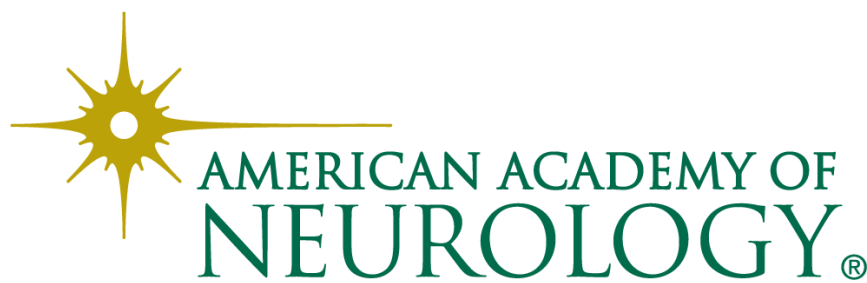

